\title{
HUBUNGAN ANTARA KOMPONEN RUMAH DENGAN KEJADIAN PENYAKIT ISPA DI WILAYAH KERJA PUSKESMAS WONOKUSUMO KOTA SURABAYA
}

\author{
Maramis Puji Darma, Khambali, Setiawan
}

\begin{abstract}
ABSTACT
Home environment give influence on upper way respiration disease (ISPA) as environment based disease indicated by improving ISPA incidence because of unhealthy home and residential. Wonokusumo public health center during last five years ISPA always positioned first ranking in Top 10 diseases with average more than 10.000 cases. This research done to recognize correlation between home component and ISPA incidence in Wonokusumo public health center Surabaya region in 2013.

Analytic research method done with case control. This research compare between case group and control group. Sample taken as many 94 houses for case group respective and control group with population 10.013 patients. Sampling technique using simple random sampling with data analysis method using chi square test.

The assessment result explain that house component assessment aspects which meet requirement house component assessment aspects are ceilings, wall, floor, living room window, and lighting. While unmeet requirement are bedroom aspects, ventilation, and kitchen fume cavity. Most of case group have home component is unmet requirements with percentage $79.8 \%$ and most of control group as many $74.5 \%$. The result of the research indicating that there are no correlation between house components and ISPA disease incidence.

Suggested health workers give information, citizen hoped to keep house cleanliness and held contest about health home in order to citizen more motivated again for more improving house that meeting healthy requirements.
\end{abstract}

Keywords : House component, ISPA incidence, health house.

\section{PENDAHULUAN}

\section{Latar Belakang}

Banyak kota-kota besar di Indonesia yang merasakan dampak negatif dari tingginya tingkat urbanisasi. Salah satu dampak negatif tersebut adalah terdapat beberapa kawasan pemukiman kumuh. Kawasan kumuh tersebut sering terjadi karena adanya golongan marginal yang memilih tinggal di pusat kota besar dan terbatasnya dana pemerintah dalam penataan dan pengelolaan kota. Pemenuhan rumah dan pemukiman yang layak huni tidaklah murah, apalagi pada kondisi seperti sekarang, justru terletak pada segi sosial ekonomi masyarakat itu sendiri. Kondisi yang demikian akan dapat menimbulkan berbagai masalah seperti tumbuhnya daerah kumuh (slum) yang tidak memenuhi syarat kesehatan baik dari segi konstruksinya maupun fasilitas kesehatan lingkungannya, sehingga akan menjadi mata rantai penularan berbagai penyakit.
Kota Surabaya saat ini merupakan salah satu kota metropolitan di Indonesia yang merasakan dampak negatif dari tingginya tingkat urbanisasi. Letak persebaran permukiman kumuh beredar hampir merata di seluruh kawasan kota Surabaya. Pada kawasan utara Kota Surabaya adalah yang teridentifikasi lebih banyak kawasan kumuhnya. Satu diantara kelurahan tersebut adalah kelurahan Wonokusumo yang terletak di Surabaya bagian utara yang tepatnya berada di Kecamatan Semampir. Kelurahan Wonokusumo memiliki potensi jumlah penduduk pendatangnya setiap tahun cenderung meningkat karena kawasannya yang strategis dan terletak di dekat Jembatan Suramadu. Meningkatnya jumlah penduduk pendatang dapat memberikan dampak berupa munculnya kawasan pemukiman kumuh di kelurahan tersebut. Kurang memadainya infrastruktur dan fasilitas 
umum serta sikap masyarakat pendatang yang cenderung kurang memperhatikan kesehatan lingkungan sekitarnya dapat turut memicu timbulnya kawasan kumuh.

Lingkungan yang berpengaruh dalam proses terjadinya ISPA adalah lingkungan perumahan, dimana kualitas rumah berdampak terhadap kesehatan anggotanya (Depkes RI, 2003). Berdasarkan laporan dari Dinas Kesehatan Kota Surabaya tahun 2011, diperoleh informasi bahwa dari 10 penyakit terbanyak di Surabaya yang menempati urutan pertama adalah ISPA dengan 578.269 kasus. Rumah dan pemukiman yang tidak sehat erat kaitannya dengan peningkatan kejadian penyakit ISPA.

Data yang diperoleh dari Puskesmas Wonokusumo Surabaya, selama lima tahun terakhir ini penyakit ISPA selalu menduduki peringkat pertama dalam urutan 10 besar penyakit dengan rata - rata lebih dari 10.000 kasus pada tiap tahunnya. Pada tahun 2008 terdapat 16.499 kasus, tahun 2009 terdapat 18.876 kasus kemudian pada tahun 2010 terdapat 18.200 kasus, tahun 2011 terdapat 11.214 kasus dan selama tahun 2012 terdapat 10.013 penderita (Puskesmas Wonokusumo, 2012). Keadaan rumah di kelurahan Wonokusumo berdasarkan hasil pengamatan peneliti memang dapat dikatakan kurang memenuhi persyaratan jika dinilai dari penilaian komponen rumah pada kartu rumah sehat. Banyak rumah yang saling berdempetan dan terletak di gang - gang yang sempit dan juga jumlah penduduk yang besar dapat menjadikan pemukiman yang kumuh pada daerah tersebut.

\section{Tujuan}

Mengetahui hubungan antara komponen rumah dengan kejadian penyakit ISPA di Wilayah Kerja Puskesmas Wonokusumo Kota Surabaya Tahun 2013.

\section{METODE PENELITIAN}

Jenis Penelitian ini termasuk analitik dengan pendekatan case control dimana penelitian ini membandingkan antara kelompok kasus dan kelompok kontrol. Populasi penelitian ini adalah seluruh rumah penderita ISPA yang berada di wilayah kerja Puskesmas Wonokusumo Surabaya dengan jumlah 10.013 penderita dan besar sampel yang akan dijadikan penelitian adalah 94 penderita untuk masing-masing kelompok kasus dan kelompok kontrol. Variabel bebas dalam penelitian ini adalah komponen rumah yang meliputi langit langit, dinding, lantai, jendela kamar tidur, jendela ruang keluarga, ventilasi, lubang asap dapur dan pencahayaan dan variabel terikatnya adalah kejadian penyakit ISPA. Data yang diambil terdiri dari data primer yaitu komponen rumah untuk kelompok kasus dan kelompok kontrol yang diperoleh dari observasi dan pengukuran sedangkan data sekunder diperoleh dari Puskesmas Wonokusumo dan Kelurahan Wonokusumo. Analisis data yang digunakan adalah pengujian stastistik yaitu chi square (X) dengan menggunakan program SPSS. 
HASIL PENELITIAN DAN PEMBAHASAN

Hasil penilaian komponen rumah pada masing - masing kelompok kasus dan kelompok kontrol dapat dilihat pada tabel berikut ini :

TABEL 1

HASIL PENILAIAN KOMPONEN RUMAH PADA MASING - MASING KELOMPOK KASUS DAN KELOMPOK KONTROL DI WILAYAH KERJA PUSKESMAS WONOKUSUMO KOTA SURABAYA

\begin{tabular}{|c|l|c|c|c|c|}
\hline \multirow{2}{*}{ No. } & \multirow{2}{*}{ Variabel } & \multicolumn{2}{|c|}{ Kelompok Kasus } & \multicolumn{2}{c|}{ Kelompok Kontrol } \\
\cline { 3 - 6 } & & TMS(\%) & MS (\%) & TMS (\%) & MS (\%) \\
\hline 1. & Langit-langit & 52,1 & 47,9 & 37,2 & 62,8 \\
\hline 2. & Dinding & 9,6 & 90,4 & 5,3 & 94,7 \\
\hline 3. & Lantai & 25,5 & 74,5 & 35,1 & 64,9 \\
\hline 4. & $\begin{array}{l}\text { Jendela Kamar } \\
\text { Tidur }\end{array}$ & 64,9 & 35,1 & 74,5 & 25,5 \\
\hline 5. & $\begin{array}{l}\text { Jendela Ruang } \\
\text { Keluarga }\end{array}$ & 46,8 & 53,2 & 48,9 & 51,1 \\
\hline 6. & Ventilasi & 43,6 & 56,4 & 57,4 & 42,6 \\
\hline 7. & $\begin{array}{l}\text { Lubang Asap } \\
\text { Dapur }\end{array}$ & 91,5 & 8,5 & 64,9 & 35,1 \\
\hline 8. & Pencahayaan & 16 & 84 & 28,7 & 71,3 \\
\hline \multicolumn{2}{|c|}{ Komponen Rumah } & 79,8 & 20,2 & 74,5 & 25,5 \\
\hline
\end{tabular}

Tabel 1 dapat menunjukkan bahwa pada kelompok kasus sebagian besar variabel penilaian yang tidak memenuhi syarat adalah langit - langit, jendela kamar tidur dan lubang asap dapur sedangkan pada kelompok kontrol sebagian besar variabel penilaian yang tidak memenuhi syarat adalah jendela kamar tidur, ventilasi dan lubang asap dapur. Hasil penilaian komponen rumah baik pada kelompok kasus maupun kelompok kontrol sama sama memiliki komponen rumah yang sebagian besar tidak memenuhi syarat.

Hasil gabungan penilaian komponen rumah pada kelompok kasus dan kelompok kontrol dapat dilihat pada tabel berikut ini :

TABEL 2

HASIL GABUNGAN PENILAIAN KOMPONEN RUMAH PADA KELOMPOK KASUS DAN KELOMPOK KONTROL DI WILAYAH KERJA PUSKESMAS WONOKUSUMO KOTA SURABAYA

\begin{tabular}{|c|l|c|c|}
\hline \multirow{2}{*}{ No. } & \multicolumn{1}{|c|}{ Variabel } & \multicolumn{2}{|c|}{ Kriteria Penilaian } \\
\cline { 3 - 4 } & \multicolumn{1}{|c|}{ TMS (\%) } & MS (\%) \\
\hline 1. & Langit-langit & 44,7 & 55,3 \\
\hline 2. & Dinding & 7,4 & 92,6 \\
\hline 3. & Lantai & 30,3 & 69,7 \\
\hline 4. & Jendela Kamar Tidur & 69,7 & 30,3 \\
\hline 5. & Jendela Ruang Keluarga & 47,9 & 52,1 \\
\hline 6. & Ventilasi & 50,5 & 49,5 \\
\hline 7. & Lubang Asap Dapur & 78,2 & 21,8 \\
\hline 8. & Pencahayaan & 22,3 & 77,7 \\
\hline
\end{tabular}


Tabel 2 dapat menjelaskan bahwa hasil gabungan penilaian komponen rumah pada kelompok kasus dan kelompok kontrol yang sebagian besar hasil penilaiannya tidak memenuhi syarat adalah jendela kamar tidur, ventilasi dan lubang asap dapur sedangkan yang memenuhi syarat adalah langit - langit, dinding, lantai, jendela ruang keluarga dan pencahayaan.

Hubungan Antara Komponen Rumah dengan Kejadian Penyakit ISPA

Hubungan antara komponen rumah dengan kejadian penyakit ISPA dapat dilihat pada tabel berikut ini :

TABEL 3

HUBUNGAN ANTARA KOMPONEN RUMAH DENGAN KEJADIAN PENYAKIT ISPA DI WILAYAH KERJA PUSKESMAS WONOKUSUMO KOTA SURABAYA

\begin{tabular}{|c|c|c|}
\hline \multirow{2}{*}{ Komponen Rumah } & \multicolumn{2}{|c|}{ Kejadian ISPA } \\
\cline { 2 - 3 } & Kelp. Kasus & Kelp. Kontrol \\
\hline \multirow{2}{*}{ Tidak Memenuhi Syarat } & 75 rumah & 70 rumah \\
& $(79,8 \%)$ & $(74,5 \%)$ \\
\hline \multirow{2}{*}{ Memenuhi Syarat } & 19 rumah & 24 rumah \\
& $(20,2 \%)$ & $(25,5 \%)$ \\
\hline \multirow{2}{*}{ TOTAL } & 94 rumah & 94 rumah \\
& $(100 \%)$ & $(100 \%)$ \\
\hline
\end{tabular}

Tabel 3 dapat menyatakan bahwa sebagian besar kelompok kasus memiliki komponen rumah yang tidak memenuhi syarat dengan persentase sebesar $79.8 \%$ (75 rumah) dan sebagian besar kelompok kontrol juga memiliki komponen rumah yang tidak memenuhi syarat dengan persentase sebesar $74.5 \%$ (70 rumah).

Uji Chi Square antara Komponen Rumah dengan Kejadian Penyakit ISPA

Uji chi square antara komponen rumah dengan kejadian penyakit ISPA dapat dilihat pada tabel berikut ini :

TABEL 4

UJI CHI SQUARE ANTARA KOMPONEN RUMAH DENGAN KEJADIAN PENYAKIT ISPA DI WILAYAH KERJA PUSKESMAS WONOKUSUMO KOTA SURABAYA

\begin{tabular}{|c|c|}
\hline Uji & Asymp. Sig. (2 sided)/ nilai p \\
\hline Pearson Chi-Square & 0.385 \\
\hline
\end{tabular}

Tabel 4 dapat menyatakan bahwa tidak ada hubungan antara komponen rumah dengan kejadian penyakit ISPA di Wilayah Kerja Puskesmas Wonokusumo Kota Surabaya Tahun 2013 karena Hipotesis nol diterima $(0.385>0.05)$.

Hubungan Komponen Rumah dengan Kejadian Penyakit ISPA

Hasil uji chi square diperoleh nilai p sebesar 0.385 yang berarti tidak ada hubungan antara komponen rumah dengan kejadian penyakit ISPA. Hal ini disebabkan karena pada kelompok kasus dan kelompok kontrol untuk hasil penilaian komponen rumah sebagian besar sama - sama tidak memenuhi syarat meskipun pada kelompok kontrol hasil untuk penilaian komponen rumah lebih baik dengan prosentase lebih kecil daripada kelompok kasus.

Sesuai dengan Profil Kota Surabaya Tahun 2010 permasalahan lingkungan perkotaan di Surabaya yang dominan saat ini adalah population and building density kota (kepadatan) yang terus meningkat, masalah persampahan, masalah sanitasi kota, dan water quality (kualitas air). Permasalahan kepadatan Kota Surabaya semakin kompleks dengan perkembangan jumlah penduduk yang sangat tinggi, terutama penduduk yang tidak tetap. Jumlah penduduk merupakan ancaman dan pressure terbesar bagi masalah lingkungan hidup. Setiap penduduk memerlukan energi, lahan dan sumber daya yang besar untuk bertahan hidup, di sisi lain setiap 
orang juga menghasilkan limbah dalam beragam bentuk. Pertambahan penduduk yang sangat tinggi di Kota Surabaya, diakui telah melampaui kemampuan daya dukung lingkungan untuk meregenerasi sendiri, sehingga berdampak pada kualitas hidup manusia yang semakin rendah.

Satu diantara permasalahan di Kota Surabaya adalah potensi jumlah penduduk yang setiap tahunnya cenderung meningkat dan sulit dikendalikan karena tingginya tingkat urbanisasi. Meningkatnya jumlah penduduk ini dapat memberikan efek yang negatif yaitu tingkat kepadatan tempat tinggal yang tinggi dan semakin sempit serta bisa juga berpengaruh terhadap efek pencemaran ligkungan yang lebih tinggi. Keadaan tempat tinggal yang padat dapat meningkatkan faktor polusi dalam rumah yang telah ada. Menurut Widoyono (2011), secara epidemiologi kejadian ISPA bisa disebabkan oleh tingkat kepadatan tempat tinggal dan pencemaran lingkungan yang ada di kawasan perkotaan serta faktor lingkungan dan perilaku penghuni rumah juga dapat mempengaruhi kejadian penyakit ISPA (Sarijan, 2005). Dalam penelitian ini komponen rumah memang tidak memiliki hubungan dengan kejadian penyakit ISPA dan hal ini berarti komponen rumah memiliki pengaruh yang kecil terhadap kejadian penyakit ISPA. Faktor keadaan komponen rumah juga dapat dilihat dan dapat dipengaruhi dari faktor perilaku penghuni rumah dan kedua faktor ini memang saling berhubungan dan memiliki pengaruh yang lebih besar terhadap kejadian penyakit ISPA serta apabila hal ini juga didukung oleh kepadatan tempat tinggal dan pencemaran lingkungan yang tinggi di suatu pemukiman maka faktor resiko terjadinya penyakit ISPA juga akan semakin besar. Tetapi pembatasan masalah dalam penelitian ini adalah peneliti hanya melakukan penelitian terhadap komponen rumah saja.

\section{KESIMPULAN DAN SARAN}

\section{Kesimpulan}

1. Kondisi komponen rumah pada kelompok kasus menunjukkan hasil bahwa komponen rumah yang tidak memenuhi syarat sebesar $79.8 \%$ dan komponen rumah yang memenuhi syarat sebesar $20.2 \%$.

2. Kondisi komponen rumah pada kelompok kontrol menunjukkan hasil bahwa komponen rumah yang tidak memenuhi syarat sebesar $74.5 \%$ dan komponen rumah yang memenuhi syarat sebesar $25.5 \%$.

3. Tidak ada hubungan antara komponen rumah dengan kejadian penyakit ISPA.

\section{Saran}

1. Memberikan penyuluhan terkait dengan kondisi komponen rumah yang memenuhi syarat kesehatan.

2. Warga diharapkan menjaga kebersihan rumah dan melakukan upaya peningkatan kesehatan lingkungan rumah dan pemukiman sekitarseperti melakukan kerja bakti masal yang dilakukan setiap 1 minggu sekali, membersihkan bagian - bagian komponen rumah seperti langit - langit, dinding, lantai, jendela, ventilasi dan lubang asap dapur secara rutin agar tidak menjadi sarang debu dan penyakit supaya nantinya tidak mengganggu kesehatan penghuninya masing-masing.

3. Mengadakan lomba tentang rumah sehat setiap 1 tahun sekali oleh puskesmas setempat agar warga semakin termotivasi lagi untuk lebih meningkatkan rumah yang memenuhi syarat kesehatan.

\section{DAFTAR PUSTAKA}

Aprinda D., 2006. Hubungan Tingkat Kesehatan Rumah Dengan Kejadian Ispa Pada Anak Balita Di Desa Labuhan Kecamatan Labuhan Badas Kabupaten Sumbawa. Surabaya, Fakultas Kesehatan Masyarakat Universitas Airlangga Surabaya.

Depkes RI, 2003. Indikator Indonesia Sehat 2010 dan Pedoman Penetapan Indikator Provinsi Sehat dan Kabupaten/Kota Sehat. www.depkes.go.id diakses pada tanggal 7 Februari 2013.

Depkes RI, 2005. Profil Kesehatan Indonesia 2005. www.depkes.go.id diakses pada tanggal 7 Februari 2013.

Keputusan Menteri Kesehatan Republik Indonesia No. 829/Menkes/SK/VII/1999 tentang Persyaratan Kesehatan Perumahan.

Keputusan Menteri Kesehatan Republik Indonesia No. 1202/Menkes/SK/VIII/2003 tentang Indikator Indonesia Sehat 2010 dan Pedoman Penetapan Indikator 
Provinsi Sehat dan Kabupaten/Kota Sehat.

Notoatmodjo, S., 2005. Metodelogi Penelitian Kesehatan. Jakarta, PT. Rineka Cipta.

Notoatmodjo, S., 2010. Metodelogi Penelitian Kesehatan. Jakarta, PT. Rineka Cipta.

Peraturan Menteri Kesehatan No. 416/Menkes/Per/IX/1990 tentang Syarat-syarat dan Pengawasan Kualitas Air.

Pemerintah Kota Surabaya. Profil Kota Surabaya, 2010. www.hrcjogja.org/images/pkk/ Kota\%20Surabaya.pdf diakses pada tanggal 1 Juli 2013.

Pedoman Teknis Penilaian Rumah Sehat. 2012. Departemen Kesehatan Provinsi Jawa Timur.

Suharmadi, 1985. Perumahan Sehat. Jakarta, Proyek Pengembangan Pendidikan Tenaga Sanitasi Pusat.

Suyono, 1985. Pokok Bahasan Modul Perumahan dan Pemukiman Sehat. Banjarmasin, Proyek Pengembangan Pendidikan Tenaga Sanitasi Pusat.
Sanropie, D. et all, 1989. Pengawasan Penyehatan Lingkungan Pemukiman. Jakarta, Depkes RI.11.

Sarijan, 2005. Hubungan Faktor Lingkungan Dan Perilaku Keluarga Terhadap Kejadian Penyakit Ispa Pada Balita Didesa Banjararjo Kecamatan Ayah Tahun 2005. Fakultas Kesehatan Masyarakat Universitas Diponegoro.

Setijaningrum, E., 2009. Pengembangan Model Pemberdayaan Masyarakat Sebagai Upaya Pengentasan Kemiskinan di Perkotaan. Jurnal Masyarakat Kebudayaan dan Politik. Edisi 1: 3.

Santjaka, A., 2011. Statistik Untuk Penelitian Kesehatan. Yogyakarta, Nuha Medika.

Sarudji, D., 2012. Kesehatan Lingkungan. Surabaya, Media IImu.

Undang-Undang Republik Indonesia Nomor 4 Tahun 1992 tentang Perumahan dan Permukiman.

Undang-Undang Republik Indonesia Nomor 36 Tahun 2009 tentang Kesehatan.

Widoyono, 2011. Penyakit Tropis. Surabaya, Erlangga. 